\title{
Educational Data Mining to Improve Decision Support on the Ratio of students and Study Groups in Elementary Schools in Indonesia using K-Means Method
}

\author{
Etika Kartikadarma, Universitas Dian Nuswantoro, Semarang, Indonesia \\ Sri Jumini, Universitas Sains Al-Qur'an, Wonosobo, Indonesia \\ Nurulisma Binti Hj. Ismail, School of Computer and Communication Engineering, Universiti Malaysia \\ Perlis, Malaysia \\ Barany Fachri, Universitas Pembangunan Panca Budi, Medan, Indonesia \\ Dadang Sudrajat, STMIK IKMI CIREBON, Cirebon, Indonesia \\ *Robbi Rahim, Sekolah Tinggi Ilmu Manajemen Sukma, Medan, Indonesia, usurobbi85@zoho.com \\ *Corresponding Author
}

\begin{abstract}
In the world of education, the process of processing space in learning activities is very important. This is in order to prevent unwanted behavior and can direct student activities. The purpose of the study was to analyze whether the mapping of regions (provinces) on the ratio of students to study groups (abbreviated as rombel) could be done by utilizing artificial intelligence techniques. The data source was obtained from the Ministry of Education and Culture which was processed by the Central Statistics Agency (abbreviated as BPS) for the academic year 2018/2019 which consisted of 34 records. The research is aimed at student to class ratios at the primary school level. The technique used is the $\mathrm{k}$ means method which is part of data mining. The analysis process was carried out with the help of Rapid Miner software. Two clusters of mapping labels were used, namely the largest student-to-class ratio cluster (K1) and the smallest student-to-class ratio cluster (K2). The analysis results show that 14 provinces are in the largest cluster (K2) with an average per class $=24.2$ and 20 provinces are in the smallest cluster $(\mathrm{K} 2)$ with an average per class $=19.1$. The validity test was carried out by testing the cluster results $(\mathrm{k}=2)$ with Davies Bouldin was 0.570 . The cluster results are optimal. The validity test was also conducted on the results of the cluster with Performance (Classification) with the results of classification error: $0.00 \%$. The results of the analysis can be used as input for the government in making policies so that the quality of human resources is increasingly competitive and can compete regionally and internationally.
\end{abstract}

Keywords: Data Mining, k-means method, clustering, student ratio, Indonesia.

Received: 03.11.2020

Accepted: 14.12 .2020

Published: 05.01.2021

\section{INTRODUCTION}

Human Resources are a very important factor in supporting economic growth [1]. In Indonesia, increasing human resources is always carried out to produce quality education graduates who have high quality competence and productivity [2,3]. One of the efforts to improve the quality of graduates is through an effective learning atmosphere for student participants. This has been regulated in the Government's policy in creating an effective learning atmosphere by issuing Permendikbud Number 22 of 2016 concerning Basic and Secondary Education Process Standards limiting the number of study groups (abbreviated as "rombel") in each educational unit and the number of students per study group[4] Development of media kocerin (Smart box interactive) to learning mathematics in Junior High School,. In the research conducted by Finn and Achilles in [2] states that small classes improve learning behavior and result in fewer class disruptions and disciplinary problems. Based on data sources from the Central Bureau of Statistics (BPS) in the BPS Catalog: 4301008 on the Portrait of Indonesian Education, mapping of regions in Indonesia regarding the ratio of students per class for primary school level to create an effective teaching and learning atmosphere and can improve the quality of graduates. There are many techniques that can be used for mapping [5,6]. One of them is Data Mining [7]. Several techniques that can be used for mapping are classification (C4.5, ID3) [8] and clustering (k-means) [9].

The purpose of this research is to map the regions in Indonesia regarding the ratio of the number of students per study group to create an effective teaching and learning atmosphere and to improve the quality of graduates. K-means is a clustering method that minimizes variations between existing data in a 
cluster and maximizes variations with existing data in other clusters [10]. Several studies that use the advantages of the k-means method are [9] on K-Means Clustering With Incomplete Data. The researcher proposes a new K-means-based clustering method that unites grouping and imputation into a single objective function. The experimental results have clearly demonstrated the effectiveness of the method that outperforms some commonly used methods for incomplete data. Next [11], In this paper, a new method is proposed to find a better initial centroid and to provide an efficient way of assigning data points to suitable clusters with reduced time complexity. The experimental results of the proposed method have much more accuracy with less computation time. Based on these advantages, it is hoped that the k-means method can map the number of students per study group in Indonesia so that the results of the analysis can be input to the government in making policies so that the quality of human resources is more competitive and can compete regionally and internationally.

\section{METHODOLOGY}

\section{Data Mining}

The related explanation of data mining is the discovery of hidden patterns and modeling using several techniques that can thoroughly explore complex relations in large sets. Data sets can be tabulated and can be implemented into other representations such as multimedia, text, images and spatial data [10]. Several data mining methods have been used by previous researchers such as K-Means, Improved K-Means, KMedoids (PAM), Fuzzy C-Means, DBSCAN, CLARANS and Fuzzy Substractive [12].

\section{K-Means Method}

The k-means method is the simplest and most widely used method for separating datasets into "k" groups [9]. The goal is to separate objects into several groups of different characteristics from one group to another [10]. The k-means method is also called the unsupervised modeling process. The following is an example of cluster results using the k-means method:

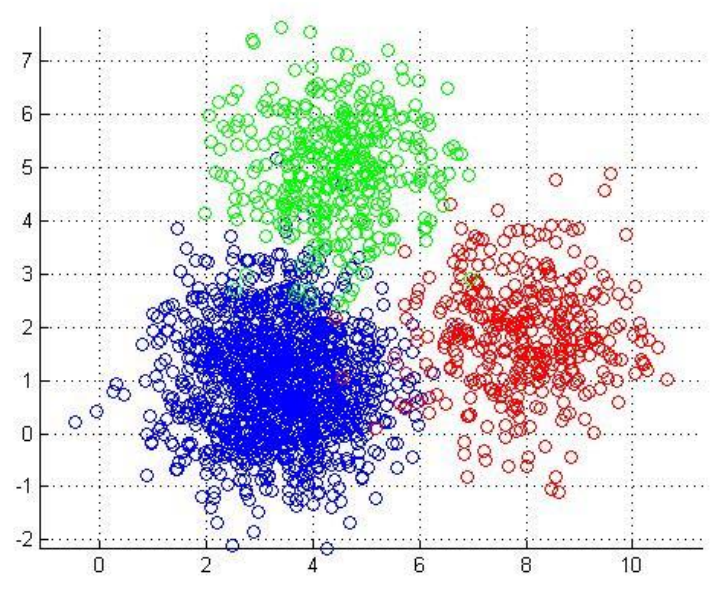

Figure 1. Clustering using the k-means method

The procedure used in optimizing using k-means is as follows [13]:

Step 1. Determine the number of clusters.

Step 2. Allocate data into clusters randomly.

Step 3. Calculate the centroid / average of the data in each cluster.

Step 4. Allocate each data to the nearest centroid / average

Step 5. Return to Step 3, if there is still data moving clusters or if the centroid value changes.

\section{Data}

The data used in the study is secondary data sourced from the Ministry of Education and Culture which is processed by the Central Statistics Agency (abbreviated as BPS) in the BPS Catalog: 4301008 on the Portrait of Indonesian Education. The research leads to student and class ratios at the primary school level for the 2018/2019 academic year which consists of 34 records. The following is the source of the research data used in mapping the area to the ratio of the number of students per study group. 
Table 1. Research data

\begin{tabular}{|ll|}
\hline Province & Student to Study Group Ratio \\
Aceh & 20 \\
North Sumatra & 23 \\
West Sumatra & 21 \\
Riau & 23 \\
Jambi & 21 \\
South Sumatra & 23 \\
Bengkulu & 20 \\
Lampung & 22 \\
Kep. Bangka Belitung & 25 \\
Kep. Riau & 24 \\
DKI Jakarta & 28 \\
West Java & 27 \\
Central Java & 22 \\
DIYogyakarta & 21 \\
East Java & 21 \\
Banten & 28 \\
Bali & 23 \\
West Nusa Tenggara & 23 \\
East Nusa Tenggara & 20 \\
West Kalimantan & 19 \\
Central Kalimantan & 16 \\
South Borneo & 18 \\
East Kalimantan & 23 \\
North Kalimantan & 20 \\
North Sulawesi & 16 \\
Central Sulawesi & 17 \\
South Sulawesi & 20 \\
Southeast Sulawesi & 19 \\
Gorontalo & 19 \\
West Sulawesi & 18 \\
Maluku & 19 \\
North Maluku & 18 \\
West Papua & 19 \\
Papua & 25 \\
& source: BPS \\
\hline Hers & 23 \\
\hline
\end{tabular}

Here's how research works using the k-means method in mapping the area to the ratio of the number of students per study group as described in Figure 2 below:

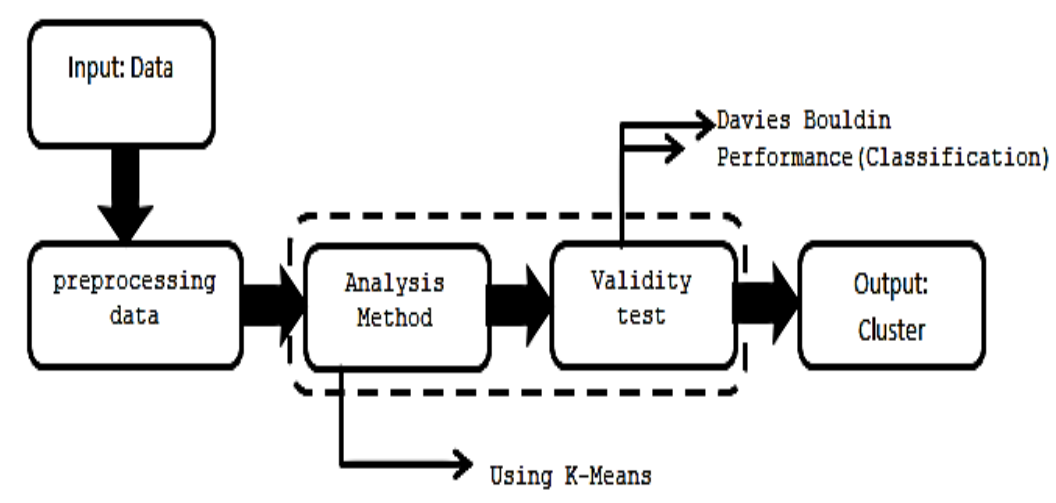

Figure 2. Research workflow

In the figure 2, it is explained that the data source was obtained from the Ministry of Education and Culture which was processed by the Central Statistics Agency (abbreviated as BPS) in excel. The data preprocessing process is carried out to see incomplete data so that when processing it gets maximum 
results. The analysis process uses the help of Rapid Miner software. The analysis process using the kmeans method is carried out. The results of the analysis were tested for validity using several parameters to see the results of the cluster formed $(K=1,2,3 . . \mathrm{n})$ and the performance of the cluster. If feasible, the cluster formed is the best cluster in this study.

\section{RESULTS AND DISCUSSION}

At this stage, the analysis process is carried out using the k-means method. Two clusters of mapping labels were used, namely the largest student-class ratio cluster (K1) and the smallest student-class ratio cluster (K2). The attributes used are the province and the cluster student ratio per class in each province. The following is the design of the k-means method using the RapidMiner software as shown in the following figure:
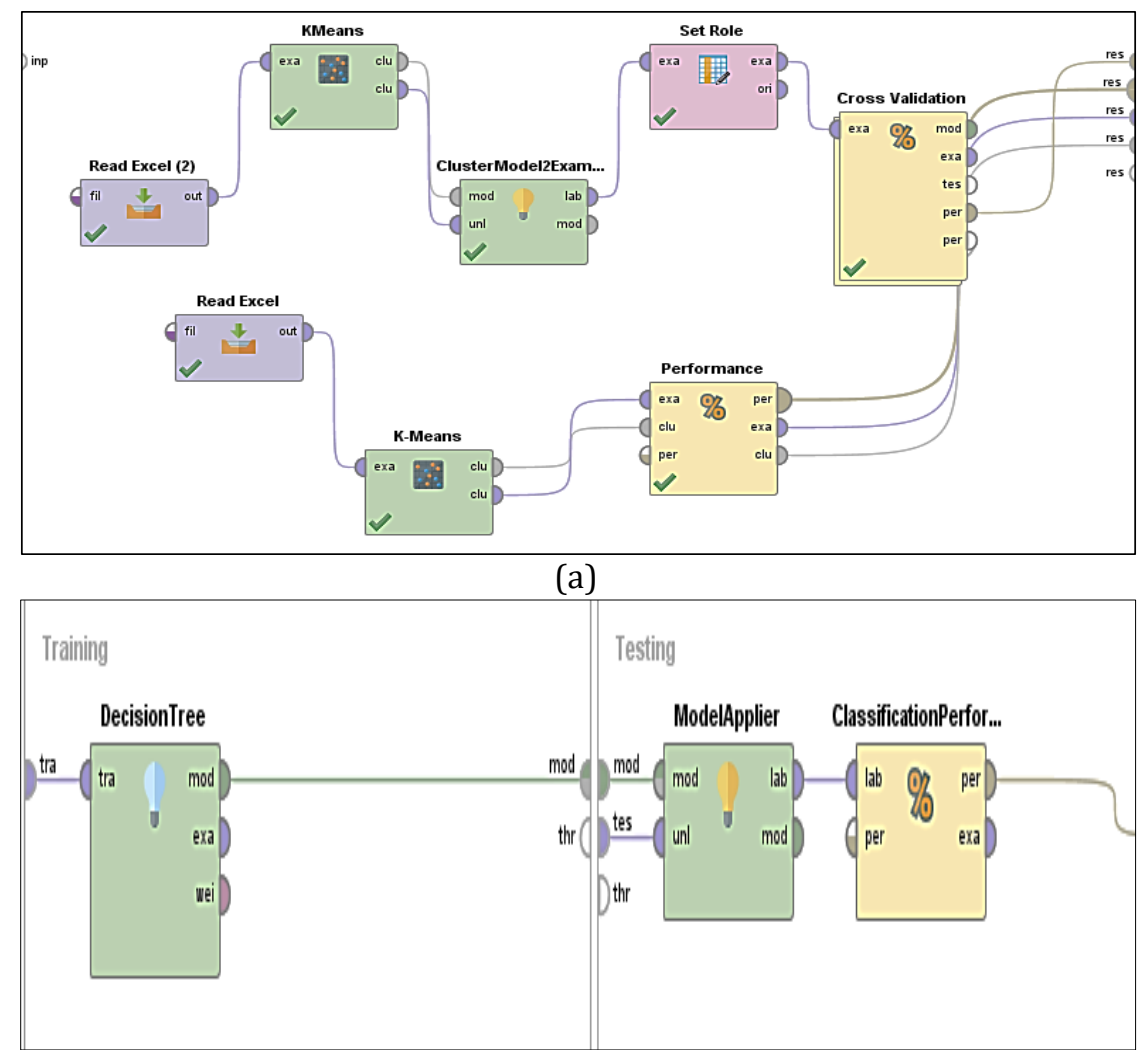

(b)

Figure 3. The k-means model in the RapidMiner design

In Figure 3 (a) the data is processed based on the input entered (.xls). By using the k-means method, a cluster mapping process is generated. In Figure 3 (b), the cluster results are tested with the Davies Bouldin Index (DBI) parameter. DBI is a reference for the cluster formed. The smaller the DBI value, the more optimal the cluster formed. Then the cluster results are re-tested with performance (classification) parameters to see the results of the accuracy (\%) of the cluster formed. The following are cluster results using the k-means method on the ratio of the number of students per study group based on province as shown in the following figure: 


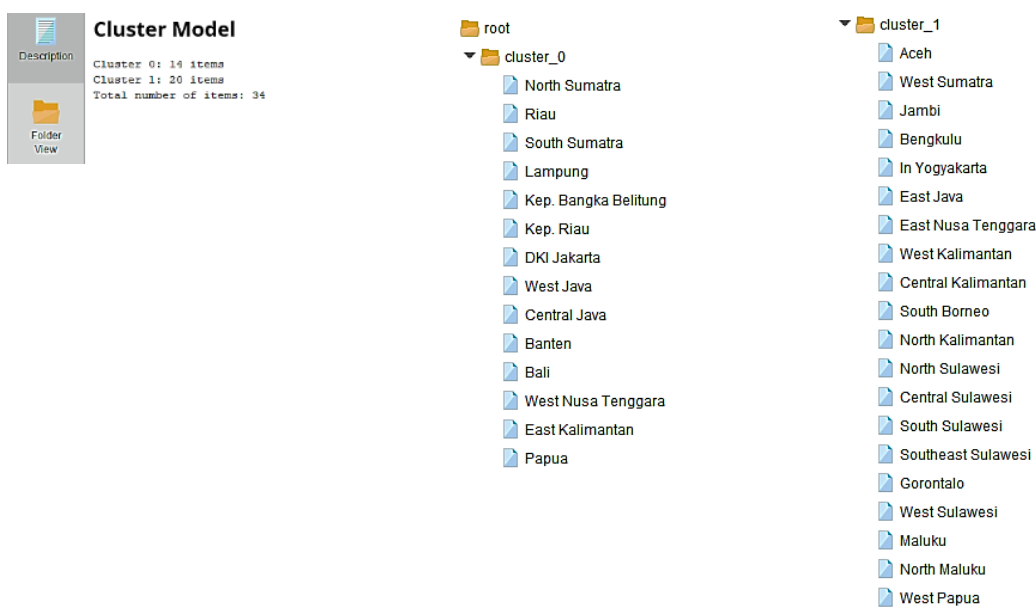

Figure 4. Results of clustering with $k$-means

In Figure 4, it can be explained that the results of the cluster show that 14 provinces are in the largest cluster student ratio per class $(\mathrm{K} 1=$ cluster_ 0$)$ and 20 provinces are in the smallest student ratio cluster per class (K2 = cluster_1). Clusters on KI are North Sumatra, Riau, South Sumatra, Lampung, Kep. Bangka Belitung, Kep. Riau, DKI Jakarta, West Java, Central Java, Banten, Bali, West Nusa Tenggara, East Kalimantan, Papua. Clusters in K2 are Aceh, West Sumatra, Jambi, Bengkulu, DI Yogyakarta, East Java, East Nusa Tenggara, West Kalimantan, Central Kalimantan, South Borneo, North Kalimantan, North Sulawesi, Central Sulawesi, South Sulawesi, Southeast Sulawesi, Gorontalo, West Sulawesi, Maluku, North Maluku, West Papua. The results of cluster determination can be seen from the final centroid which is formed as shown in the following figure:

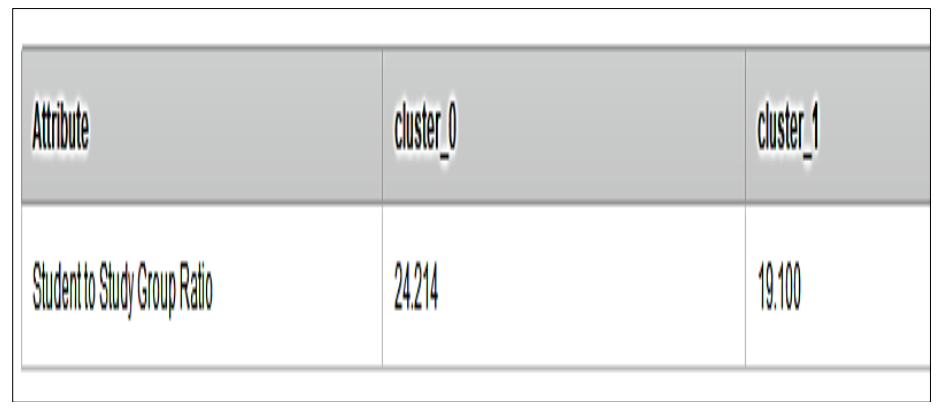

Figure 5. The final centroid results

In Figure 5 the final result of the centroid is 24,214 for the largest cluster (cluster_0) and 19.1 for the smallest cluster (cluster_1).

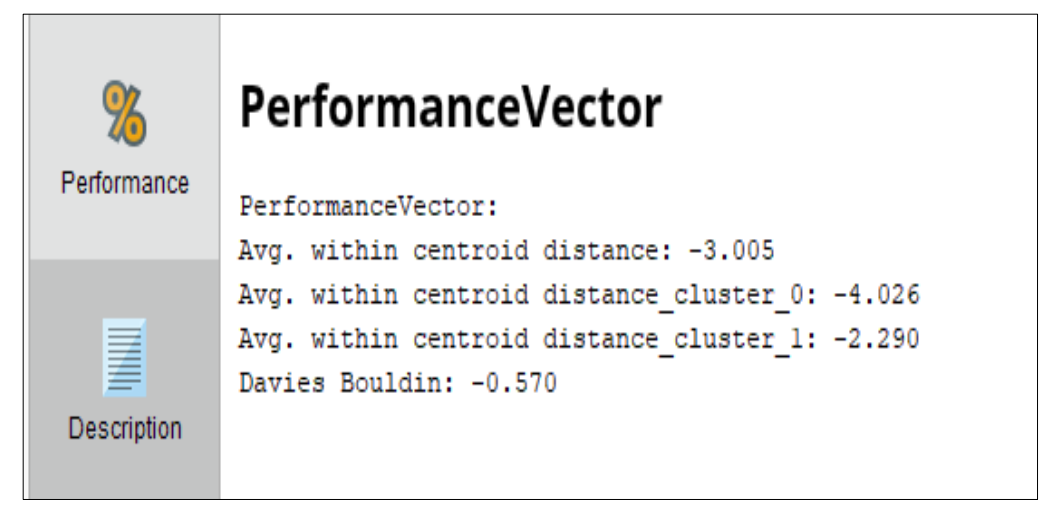

Figure 6. Performance of the Davies Bouldin Index 
In figure 6, the test results using the Davies Bouldin Index parameter is 0.570 with a value of $k=2$. The results of the cluster formed are optimal. Because the smaller the generated DBI value, the better the cluster results will be formed.

\begin{tabular}{|l|l|l|l|}
\hline \multicolumn{2}{|l|}{ classification_error:0.00\%+1-0.00\% (micro average: $0.00 \%$ ) } & \\
\hline & true cluster_1 & true cluster__ & class precision \\
\hline pred. cluster_1 & 20 & 0 & $100.00 \%$ \\
\hline pred. cluster_0 & 0 & 14 & $100.00 \%$ \\
\hline class recall & $100.00 \%$ & $100.00 \%$ & \\
\hline
\end{tabular}

Figure 7. Performance of the performance (classification)

In figure 7 , the test results use performance (classification) where the classification error $=0 \%$, which means that all data can be predicted correctly. The following is the complete cluster results on mapping the ratio of the number of students per class at the elementary school level using the k-means method as shown in the following table:

Table 2. The results of the RapidMiner export file to Excel

\begin{tabular}{|lll|}
\hline Ratio & Province & cluster \\
20 & Aceh & cluster_1 \\
23 & North Sumatra & cluster_0 \\
21 & West Sumatra & cluster_1 \\
23 & Riau & cluster_0 \\
21 & Jambi & cluster_1 \\
23 & South Sumatra & cluster_0 \\
20 & Bengkulu & cluster_1 \\
22 & Lampung & cluster_0 \\
25 & Kep. Bangka Belitung & cluster_0 \\
24 & Kep. Riau & cluster_0 \\
28 & DKI Jakarta & cluster_0 \\
27 & West Java & cluster_0 \\
22 & Central Java & cluster_0 \\
21 & DI Yogyakarta & cluster_1 \\
21 & East Java & cluster_1 \\
28 & Banten & cluster_0 \\
23 & Bali & cluster_0 \\
23 & West Nusa Tenggara & cluster_0 \\
20 & East Nusa Tenggara & cluster_1 \\
19 & West Kalimantan & cluster_1 \\
16 & Central Kalimantan & cluster_1 \\
18 & South Borneo & cluster_1 \\
23 & East Kalimantan & cluster_0 \\
20 & North Kalimantan & cluster_1 \\
16 & North Sulawesi & cluster_1 \\
17 & Central Sulawesi & cluster_1 \\
20 & South Sulawesi & cluster_1 \\
19 & Southeast Sulawesi & cluster_1 \\
19 & Gorontalo & cluster_1 \\
18 & West Sulawesi & cluster_1 \\
19 & Maluku & cluster_1 \\
18 & North Maluku & cluster_1 \\
19 & West Papua & cluster_1 \\
25 & Papua & cluster_0 \\
\hline & & \\
25 & &
\end{tabular}




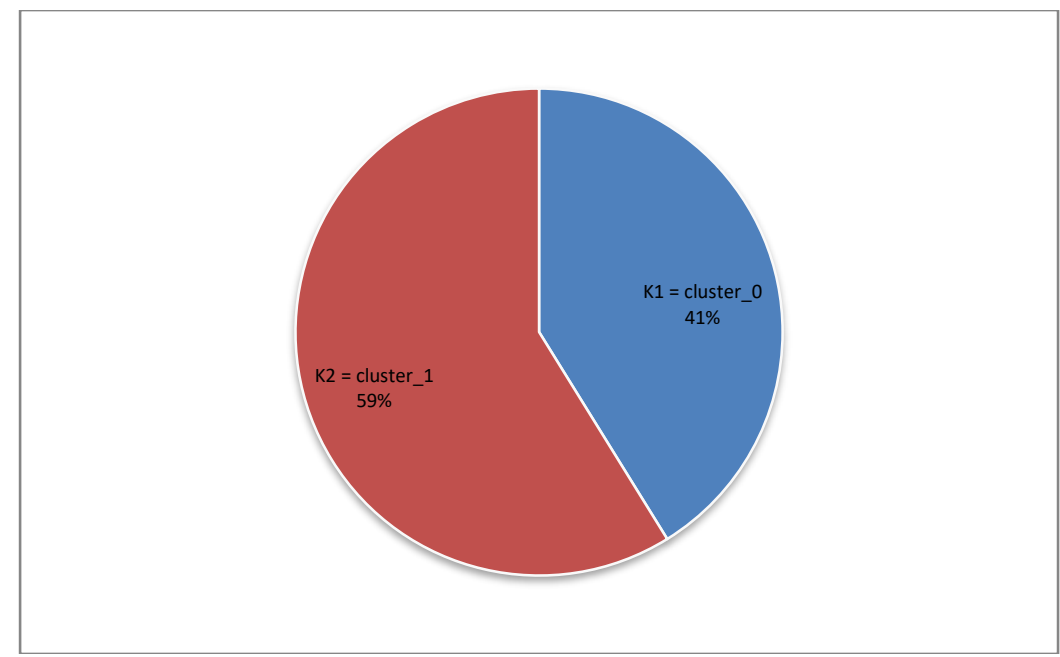

Figure 8. Percentage of cluster results

In Figure 8, it is explained that the percentage cluster ratio of students per class is based on province. The analysis results show that 14 provinces are in the largest cluster (K2) with an average per class $=24.2$ and 20 provinces are in the smallest cluster (K2) with an average per class $=19.1$. The following is a mapping graph with bars and scatter as shown in the following image:

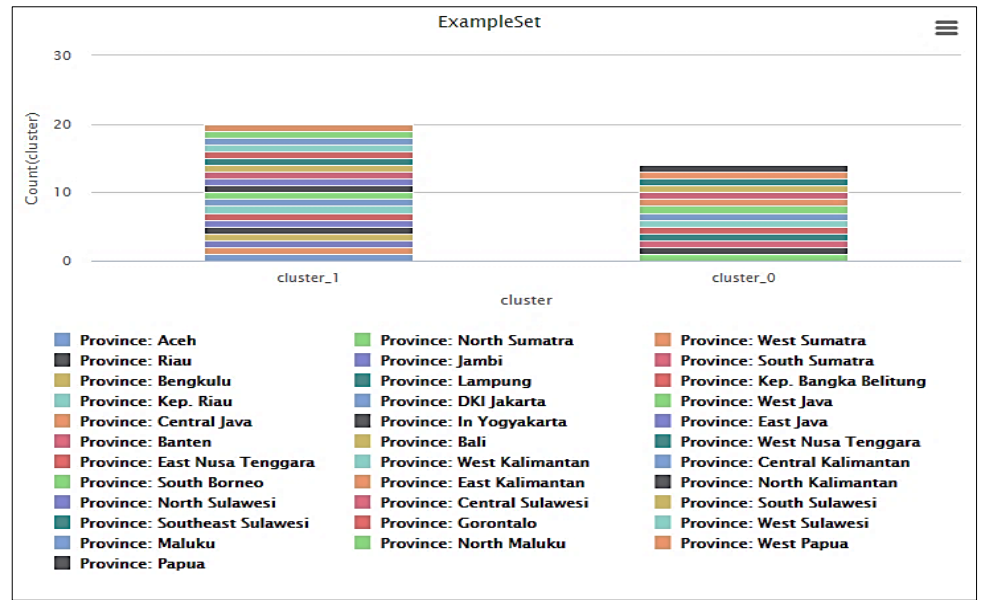

(a)

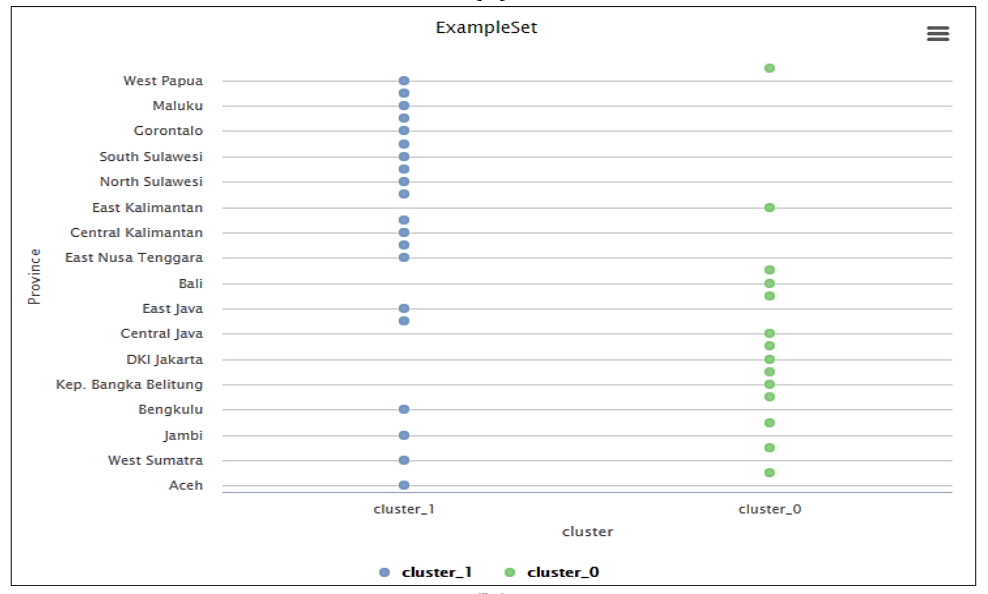

(b)

Figure 9. Visualization of clustering results with bat chat and scatter plotter (a) (b) 


\section{CONCLUSION}

The results of the study concluded that the k-means method can be applied to mapping the number of students per study group at the primary school level by province. The results of the analysis show that 14 provinces are in the largest cluster (K2) with an average per class $=24.2$ and 20 provinces are in the smallest cluster (K2) with an average per class $=19.1$. The validity test was done by testing the cluster results $(\mathrm{k}=2)$ with Davies Bouldin was 0.570 . The cluster results are optimal. The validity test was also carried out on the results of the cluster with Performance (Classification) with the results of classification error: $0.00 \%$.

\section{REFERENCES}

N.S. Perdana, Analisis Capaian Rombongan Belajar Di Provinsi Lampung Tahun 2018 Dalam Upaya Implementasi Permendikbud Nomor 17 Tahun 2017, Dewantara. V (2018) 1-16.

N.S. Perdana, Pengelolaan Ukuran Rombongan Belajar Dan Siswa Per- Rombel dalam Upaya Peningkatan Kualitas Lulusan Menyongsong Society 5.0, in: Pros. SEMDIKJAR (Seminar Nas. Pendidik. Dan Pembelajaran), 2019: pp. 570-580.

Sunandar, A. Buchori, N.D. Rahmawati, W. Kusdaryani, Mobilemath (mobile learning math) media design with seamless learning model on analytical geometry course, Int. J. Appl. Eng. Res. 12 (2017) 8076-8081. https://www2.scopus.com/inward/record.uri?eid=2-s2.085040255903\&partnerID=40\&md5=e3d36bcb06c17d82ebd20ff6c483f1ff.

Sunandar, A. Buchori, N.D. Rahmawati, Development of media kocerin (Smart box interactive) to learning mathematics in Junior High School, Glob. J. Pure Appl. Math. (2016).

B. Supriyadi, A.P. Windarto, T. Soemartono, Mungad, Classification of natural disaster prone areas in Indonesia using K-means, Int. J. Grid Distrib. Comput. 11 (2018) 87-98.

S. Sriyanto, A. Buchori, A. Handayani, P.T. Nguyen, H. Usman, Implementation multi factor evaluation process (MFEP) decision support system for choosing the best elementary school teacher, Int. J. Control Autom. (2020).

R.A. Haraty, M. Dimishkieh, M. Masud, An enhanced k-means clustering algorithm for pattern discovery in healthcare data, Int. J. Distrib. Sens. Networks. 2015 (2015). https://doi.org/10.1155/2015/615740.

A. Waluyo, H. Jatnika, M.R.S. Permatasari, T. Tuslaela, I. Purnamasari, A.P. Windarto, Data Mining Optimization uses C4.5 Classification and Particle Swarm Optimization (PSO) in the location selection of Student Boardinghouses, IOP Conf. Ser. Mater. Sci. Eng. 874 (2020) 1-9. https://doi.org/10.1088/1757-899X/874/1/012024.

S. Wang, M. Li, N. Hu, E. Zhu, J. Hu, X. Liu, J. Yin, K-Means Clustering With Incomplete Data, IEEE Access. 7 (2019) 69162-69171. https://doi.org/10.1109/ACCESS.2019.2910287.

H.L. Sari, D. Suranti, L.N. Zulita, Implementation of k-means clustering method for electronic learning model, J. Phys. Conf. Ser. 930 (2017). https://doi.org/10.1088/1742-6596/930/1/012021.

C. Zhang, S. Xia, K-means clustering algorithm with improved initial center, Proc. - 2009 2nd Int. Work. Knowl. Discov. Data Mining, WKKD 2009. 1 (2009) 790-792. https://doi.org/10.1109/WKDD.2009.210.

D. Marlina, N. Lina, A. Fernando, A. Ramadhan, Implementasi Algoritma K-Medoids dan K-Means untuk Pengelompokkan Wilayah Sebaran Cacat pada Anak, J. CoreIT J. Has. Penelit. Ilmu Komput. Dan Teknol. Inf. 4 (2018) 64. https://doi.org/10.24014/coreit.v4i2.4498.

P. Arora, Deepali, S. Varshney, Analysis of K-Means and K-Medoids Algorithm for Big Data, Phys. Procedia. 78 (2016) 507-512. https://doi.org/10.1016/j.procs.2016.02.095. 